\title{
Methodology of diesel particulate filter testing on test bed for non-road engine application
}

ARTICLE INFO

Received: 18 August 2021

Revised: 31 August 2021

Accepted: 12 September 2021

Available online: 20 December 2021
This paper describes the methodology and test results of diesel particulate filter (DPF) functional testing performed on non-road compression ignition engine application installed on test bed. The scope of work included testing of various DPF regeneration strategies, backpressure and balance point tests and emission performance evaluation during a legislative test cycle. The aim of this study was to observe and investigate the influence of raw exhaust gas parameters on DPF functionality in terms of filtration efficiency, soot loading, type and duration of the regeneration and emission performance. Under investigation was the capability of soot burning rate and fuel penalty.

The DPF sample under test was part of the complete exhaust aftertreatment system (ATS) which consisted of: a diesel oxidation catalyst (DOC), a DPF and a selective catalytic reduction system (SCR) with urea dosing and ammonia slip catalyst (ASC). Testing was carried out on a heavy-duty diesel engine installed on a test stand with a dynamic dynamometer and equipped with an emission bench. The test program allowed to assess the engine matching to exhaust aftertreatment system with regard to emissions compliance, in-service operation and necessary engine control unit (ECU) calibration works. The results show the influence of the DPF regeneration strategy on its duration and on the soot mass burn rate. Passive DPF regeneration was a favorable mode of DPF cleaning, due to lack of fuel penalty and lower aging impact on the entire ATS. Optimization of soot flow rate, exhaust gas temperature and the chemistry of the DOC/DPF was further recommended to ensure the longterm durability of the entire system.

Key words: exhaust aftertreatment, diesel particulate filter, soot oxidation, passive regeneration, emission

This is an open access article under the CC BY license (http://creativecommons.org/licenses/BY/4.0/)

\section{Introduction}

Registrations of new heavy duty vehicles with diesel engines remain dominant in terms of market share in EU in 2020 and amount to more than $96 \%$ [1]. The adverse effect of exhaust emissions on human health and the environment $[2,3]$ have forced EU institutions to act ever stricter towards the zero-emission, carbon neutral driveline solutions. Under the tightening regulatory framework, vehicle manufacturers introduce advanced and highly efficient exhaust aftertreatment techniques adapted to various diesel engine applications. The regular approach for $\mathrm{NO}_{\mathrm{x}}$ reduction relies on utilization of high/low pressure exhaust gas recirculation (EGR) systems at the expense of increased emission of particulate matter, which is afterwards trapped and removed by a DPF filter. Different DPF configurations are available $[4,5]$, but wall-flow type filters are the most widely used. Wall-flow filters are honey-comb monoliths with parallel channels plugged alternately at each end to force the exhaust gas to pass through the porous filter wall, where soot is retained. Therefore, the exhaust backpressure increases in the exhaust line, penalizing fuel consumption, but the high filtering efficiency (in excess of 90\%) makes DPF filters essential for complying with emission standards. Notably, the fuel economy penalty of DPF in heavy-duty vehicle can minimalized by the optimization of filter implementation. The experimental study of in-service operation of urban buses and intercity coaches reported as low fuel economy penalty as $0.6-1.8 \%$ [6]. When the soot accumulated reaches a threshold, fuel post-injections are commenced to increase periodically the exhaust gas temperature up to $650^{\circ} \mathrm{C}$ and to oxidize the soot collected inside the filter (active regeneration). DPF systems are designed to regenerate also continuously during the regular operation of the engine (passive regeneration), where the source of heat is the exhaust gas stream itself. This type of filter usually incorporates a form of catalysts to lower the soot oxidation temperature. Apart from temperature, other factors such as the exhaust gas (composition, flow rate) and the physicochemical properties of soot affect the regeneration process.

In the present work, a dedicated DPF sample was installed on a Euro VI diesel engine and tested on an engine dyno under transient and steady-state operating conditions. The test results obtained allowed evaluations of the filter functionality and its matching with a non-road engine application, under various work modes. The DPF was evaluated as part of the entire exhaust line, to ensure the required reliability, trouble free operation and compliance with emission standards.

\section{Test method and facilities}

\subsection{Unit under test}

The DPF under test was a part of complete ATS including a DOC (upstream DPF) and an SCR system with an ASC converter (downstream DPF). The filter substrate was of ceramic structure, coated with catalytic layer to enhance passive regeneration. The basic DPF parameters are shown in Table 1.

Table 1. Parameters of DPF under test

\begin{tabular}{|c|c|}
\hline Parameter & Value \\
\hline Volume & $4.2 \mathrm{dm}^{3}$ \\
\hline Cell density & $350 \mathrm{cpsi}$ \\
\hline Relative concentration of PGM & $5 \mathrm{~g} / \mathrm{ft}^{3}$ \\
\hline
\end{tabular}


For the test activities, a heavy duty diesel engine was used with the maximum power of $150 \mathrm{~kW}$ and peak torque of $650 \mathrm{Nm}$. The engine featured a common rail type, direct injection fuel system and was equipped with an open ECU and ETAS/INCA interface that allowed the ECU calibration to be modified for specific test purposes.

\subsection{Test bed instrumentation}

The engine with ATS were installed on an engine test bed equipped with AVL Fully Dynamic AC Dyno (APA 204/E) of max. power of $220 \mathrm{~kW}$ and max. torque of 934 $\mathrm{Nm}$. The test bed automation system was the AVL Puma Open 1.5.3 with iGEM 1.5 package, capable of automatically executing the NRSC and NRTC legislative cycles and following the requirements of ECE Reg. 49 with corresponding EU, ISO and EPA directives.

Testing of various regeneration strategies required engine calibration adjustment; therefore, an external ECU interface ETAS and INCA 7.2 were used. Stable and repeatable DPF temperature at a given setpoint value was achieved by continuous adjustment of the ECU parameters, mainly the timing of fuel post injection and the fuel quantity expressed in $\mathrm{mg} / \mathrm{stroke}$.

Emission analysis was carried out by the raw/undiluted exhaust gas measurement method. The exhaust gas flow was calculated based on measurement from an air flow meter and a fuel meter. For the purposes of the study, three emission sampling points were installed on the exhaust line. The first sampling point was placed at the engine outlet; the second one was located downstream of the DOC and before the DPF; the third emission port was positioned downstream of the DPF, before the SCR catalyst.

Additionally, for analysis and monitoring purposes, temperature and pressure sensors were installed at each sampling point on the exhaust line.

An overview of engine and exhaust system layout on test bed is shown in Fig. 1.

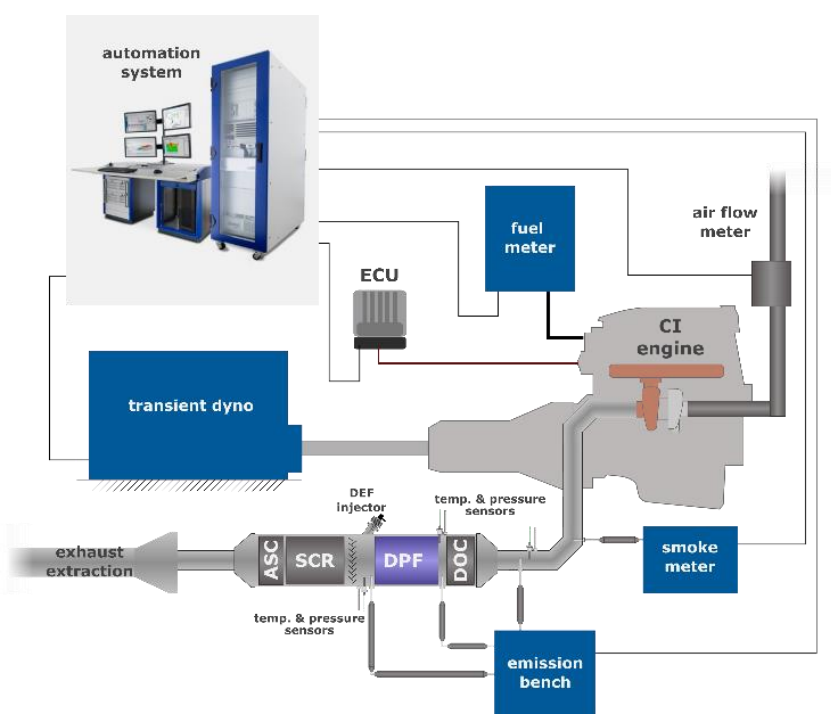

Fig. 1. Engine and exhaust system layout on test bed

The emission bench used was an AVL AMA i60 device equipped with a set of specific gas analyzers with the measuring ranges shown in Table 2. Additionally, for measurement of particulate, an AVL micro soot sensor and an AVL smoke meter were installed on the exhaust line.

Table 2. Emission analyzers ranges

\begin{tabular}{|c|c|c|}
\hline \multirow{2}{*}{$\begin{array}{c}\text { Analyzer } \\
\text { (principle of operation) }\end{array}$} & \multicolumn{2}{|c|}{ Range of measurement } \\
\cline { 2 - 3 } & Low & High \\
\hline $\mathrm{CO}_{2}$ (NDIR) & $0-0.5 \%$ & $0-20 \%$ \\
\hline $\mathrm{CO}_{\text {(NDIR) }}$ & $0-50 \mathrm{ppm}$ & $0-5000 \mathrm{ppm}$ \\
\hline $\mathrm{O}_{2}$ (PMD) & $0-1 \%$ & $0-25 \%$ \\
\hline $\mathrm{NO}_{\mathrm{x}}$ (CLD) & $0-10 \mathrm{ppm}$ & $0-10000 \mathrm{ppm}$ \\
\hline $\mathrm{NO}(\mathrm{CLD})$ & $0-10 \mathrm{ppm}$ & $0-10000 \mathrm{ppm}$ \\
\hline $\mathrm{THC}(\mathrm{FID})$ & $0-300 \mathrm{ppm} \mathrm{C1}$ & $0-60000 \mathrm{ppm} \mathrm{C1}$ \\
\hline $\mathrm{CH}_{4}$ (FID) & $0-30 \mathrm{ppm} \mathrm{C1}$ & $0-20000 \mathrm{ppm} \mathrm{C1}$ \\
\hline
\end{tabular}

\subsection{Test method}

The DPF functionality and characteristic were evaluated under the following test procedures:

- NRSC - Non Road Stationary Cycle,

is the name of ISO 8178 homologation stationary test cycle used for emission certification and/or type approval testing for non-road engine applications. The NRSC starts with hot engine conditions and represents a sequence of several steady-state modes with different weighting factors [7-10].

- $\quad$ NRTC - Non Road Transient Cycle is a transient driving cycle for mobile non-road diesel engines. The test is used internationally for emission certification and/or type approval process. The normalized engine speed and torque during the NRTC test are shown in Fig. 2.

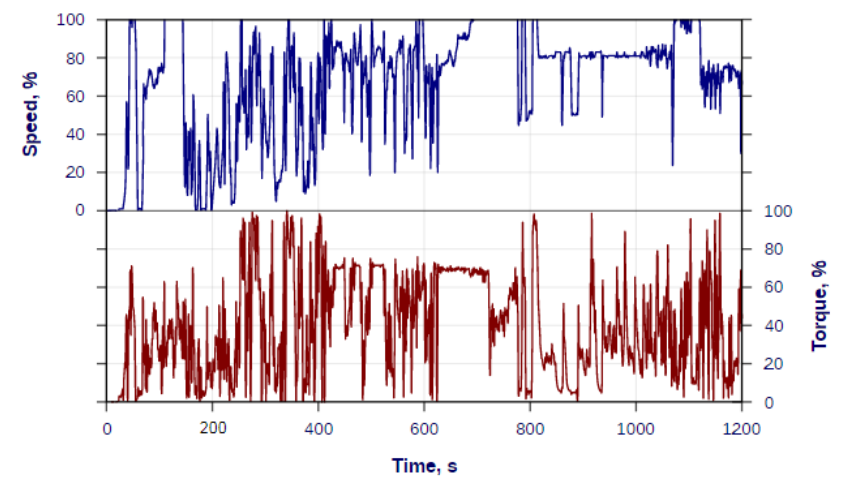

Fig. 2. Normalized speed and torque over NRTC cycle [10]

The NRTC is run twice, from a cold and a hot start, with a 20-minute soak period between the tests. The cold start weighting factors are $10 \%$ in the EU and $5 \%$ in the United States.

- Balance point test of the DOC-DPF system. The balance point test allows determination of the particle matter (PM) oxidation capability in the filter during normal engine operation - i.e., without fuel post injection used for active filter regeneration. This type of PM oxidation is referred to as passive filter regeneration. The balance point of a given DPF is understood as the lowest exhaust gas temperature at which the gas pressure drop across the filter remains constant over the time. This means that at the balance point conditions, the rate of passive regeneration of the filter is in equilibrium with the rate of PM inlet flow to the filter.

In the case of a steadily increasing DPF pressure drop, the filter is at an unfavorable operating point, as the exhaust 
temperature is too low for passive regeneration to occur efficiently and thus the soot loading in the DPF increases.

Finally, the case of a steadily decreasing DPF pressure drop signifies that the temperature of the filter allows the soot to oxidize at a greater rate than that at which it continually accumulates in the filter. Passive filter regeneration at the lowest possible gas temperature is of key importance to reducing the number of active regeneration events, thus to limiting the fuel penalty, thermal stress and aging of the exhaust system and the dilution of lubrication oil. The last point occurs if fuel post injection is used during the exhaust stroke in order to heat up the exhaust.

The regeneration of diesel particulate filters involves the oxidation of solid particulates to gaseous products, preferably to carbon dioxide $\left(\mathrm{CO}_{2}\right)$. Depending on the DPF system design and on the engine operating conditions, the oxidation of carbon in diesel soot can occur via reactions with $\mathrm{O}_{2}$ or nitrogen dioxide $\left(\mathrm{NO}_{2}\right)$. Oxygen is present in diesel exhaust at sufficient concentrations under nearly all operating conditions. However, relatively high temperatures are necessary to achieve sufficient regeneration rates with $\mathrm{O}_{2}$.

The rate of soot oxidation can be increased, and the regeneration temperature decreased, if an oxidant more active than oxygen could be introduced to the particulate filter. It was found that nitrogen dioxide can oxidize diesel particulate at higher rates than oxygen [11]. Carbon in diesel soot is oxidized by oxygen with noticeable reaction rates at temperatures above $550^{\circ} \mathrm{C}$. With $\mathrm{NO}_{2}$, the process occurs at temperatures as low as $250^{\circ} \mathrm{C}$, as illustrated in Fig. 3 [12].

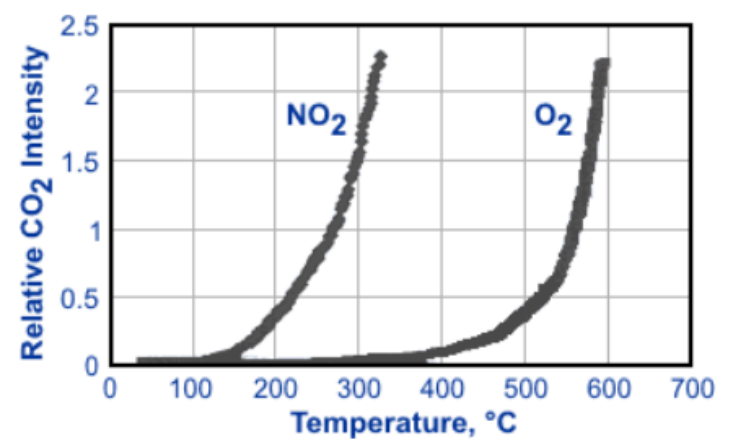

Fig. 3. Oxidation of PM by oxygen and nitrogen dioxide [13]

The presence of $\mathrm{NO}_{2}$ in exhaust gas is essential for an efficient passive regeneration process therefore, the $\mathrm{NO}_{2}$ concentration must be increased. The $\mathrm{NO}_{2}$ formation is realized by catalytic oxidation of $\mathrm{NO}$ to $\mathrm{NO}_{2}$ in the DOC placed upstream of the DPF. The DOC does not reduce the total $\mathrm{NO}_{\mathrm{x}}$ concentration in the exhaust gas, but increases the $\mathrm{NO}_{2} / \mathrm{NO}_{\mathrm{x}}$ ratio. Oxidation of soot by $\mathrm{NO}_{2}$ is the dominant mechanism of passive DPF regeneration.

- Filter pressure drop test

The test was run to determine the pressure drop curve and thus the exhaust flow resistance across the combined DOC and DPF converters. The pressure drop test was performed for the clean exhaust system condition, which was achieved by performing the active regeneration procedure and a preconditioning step at engine full load conditions. The test was composed of steady state engine running points with stepwise increased exhaust mass flow rate, recorded as a function of DOC-DPF system pressure drop. This type of test can be also used for comparison purposes between competitive systems' solutions.

- Filter loading and regeneration test

The test aimed at evaluation of filter regeneration efficiency and consisted of two phases: the filter soot loading and the regeneration phase. The filter loading method was elaborated to ensure sufficiently fast DPF loading with soot to reach the target amount. The optimal soot loading point was characterized by three features:

- high engine out soot emission,

- high exhaust gas flow,

- low exhaust gas temperature (to limit filter passive regeneration).

To set the optimal engine operating point, several trial measurements on various engine speed and load condition were carried out. Due to the fact that particulate matter deriving from the combustion process are composed mainly of elementary carbon (C), known as "black soot", the soot loading and $\mathrm{C}$ value on each measured point were calculated according to Equations 1 and 2 [14], respectively:

$$
\begin{gathered}
\text { Soot loading }=\frac{\mathrm{C}}{\rho_{\text {exh }}} \cdot \mathrm{G}_{\text {exh }}[\mathrm{g} / \mathrm{h}] \\
\mathrm{C}=\frac{1}{0.405} \cdot 4.95 \cdot \mathrm{FSN} \cdot \mathrm{e}^{(0.38 \cdot \mathrm{FSN})}\left[\mathrm{mg} / \mathrm{m}^{3}\right]
\end{gathered}
$$

where: $G_{\text {exh }}-$ exhaust mass flow, $\rho_{\text {exh }}-$ exhaust density, FSN - filter smoke number.

The composition of the PM from diesel combustion is shown schematically in Fig. 4.

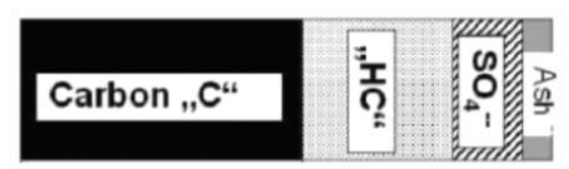

Fig. 4. Composition of PM [15]

Each time before the soot loading phase commenced, the filter was cleaned up by passive regeneration with high gas temperature conditions. The filter was then weighed in its warm condition to establish the zero soot mass level. The duration of the soot loading phase depended on the desired soot level in the filter. The filter loading was followed by DPF weighing in its warm condition to define the actual amount of PM collected inside the filter.

The second phase was the filter regeneration with different strategies. Both active and passive regenerations were tested, with various combinations of exhaust gas temperature and regeneration durations.

After each regeneration during the second phase, the DPF was weighed in its warm condition to define the amount of oxidized PM.

\section{Test results and discussion}

\subsection{NRSC test results}

The purpose of NRSC test run to assess the overall emission performance of engine and exhaust system. Fig. 5 presents engine speed, torque profiles and regulated gaseous emissions measured at the DPF outlet. The CO and HC 
values remained at very low levels of up to $10 \mathrm{ppm}$, although single emission spikes were recorded. In contrast, the $\mathrm{NO}_{\mathrm{x}}$ concentration ranged between $150-1400 \mathrm{ppm}$, but notably those values were measured upstream of the SCR system.

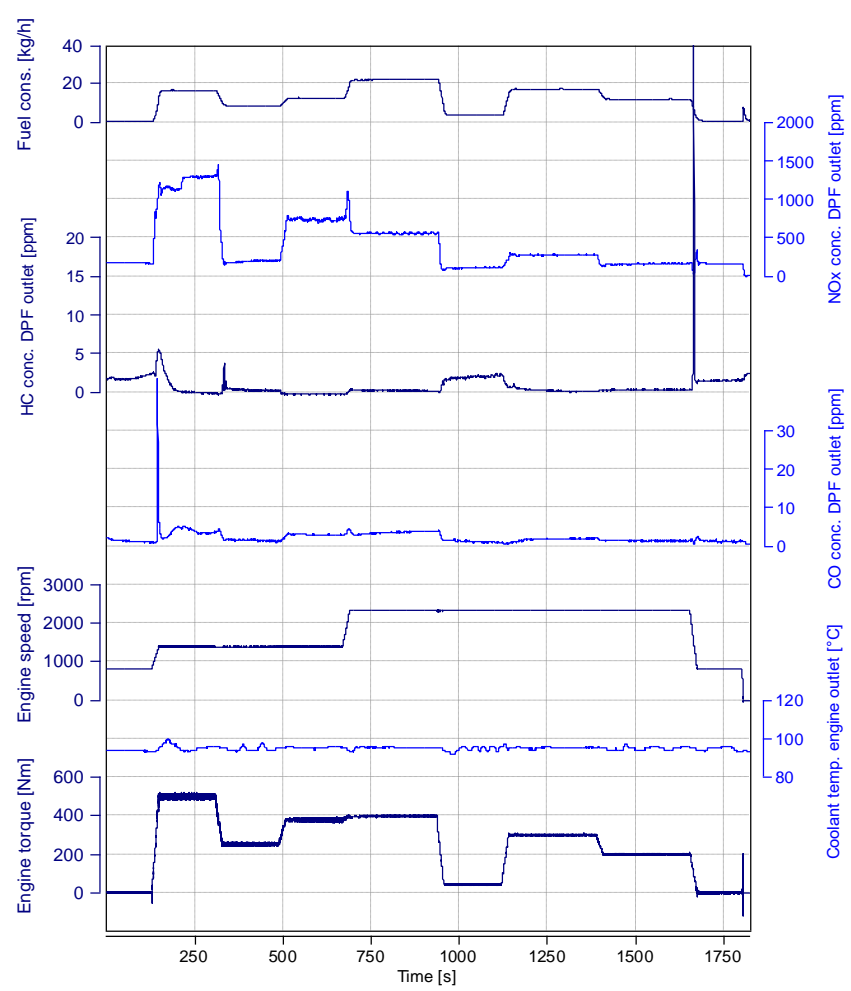

Fig. 5. NRSC test profile

The NRSC cycle lasted 1800s and consisted of 9 operating modes, calculated on the basis of a dynamic full load curve run on the engine. The operating modes cover a wide range of the in-field engine operation area at steady-state conditions.

\subsection{NRTC test results}

Subsequently, the emission behavior was evaluated for transient conditions under the cold/hot NRTC test. The cold NRTC phase of was started at an engine coolant temperature of $23^{\circ} \mathrm{C}$; the test profile is illustrated in Fig. 6. Increased $\mathrm{HC}$ and $\mathrm{CO}$ concentration was measured over the first ca. $100 \mathrm{~s}$, corresponding to the time period necessary for the DOC to achieve its light-off temperature. Until engine warm up to working temperature single spikes in $\mathrm{CO}$ concentrations were spotted. Similarly to the NRSC run, the $\mathrm{NO}_{\mathrm{x}}$ measurement took place upstream of the SCR - and therefore the $\mathrm{NO}_{\mathrm{x}}$ concentration remained high throughout the test.

Although the reduction rate of the total $\mathrm{NO}_{\mathrm{x}}$ concentration in the DOC-DPF system was found to be negligible, it influenced the $\mathrm{NO}_{\mathrm{x}}$ composition in terms of the $\mathrm{NO}_{2}$ share. The $\mathrm{NO}_{2}$ concentration at the engine outlet and DPF inlet locations are compared in Fig. 7.

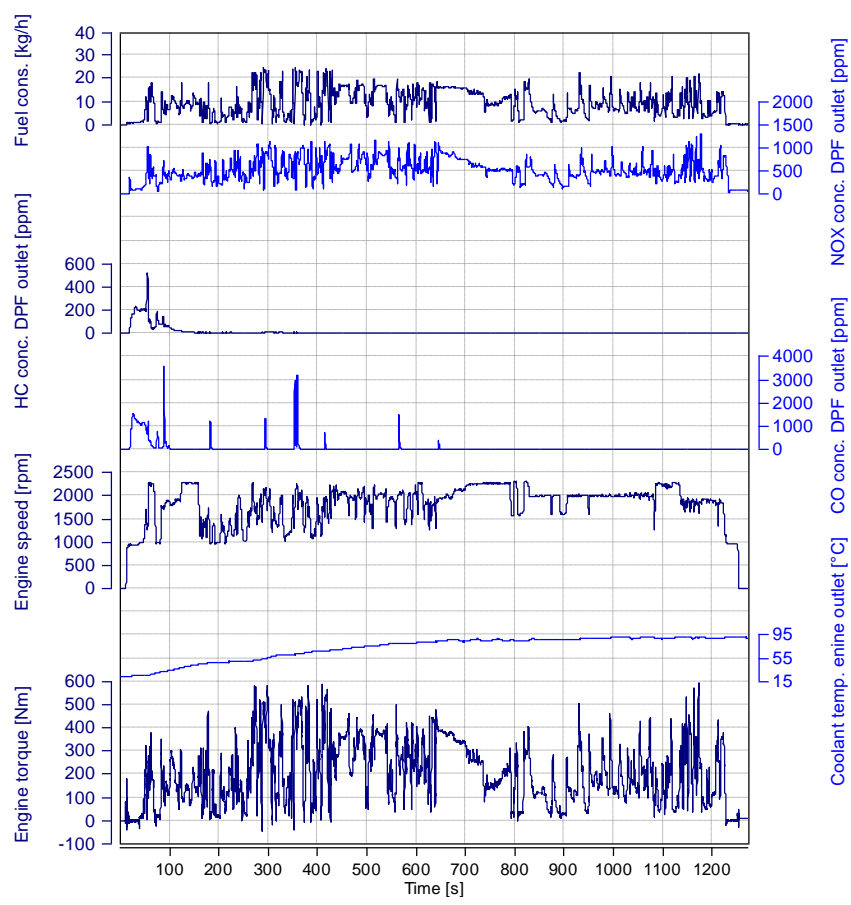

Fig. 6. NRTC test profile - cold phase

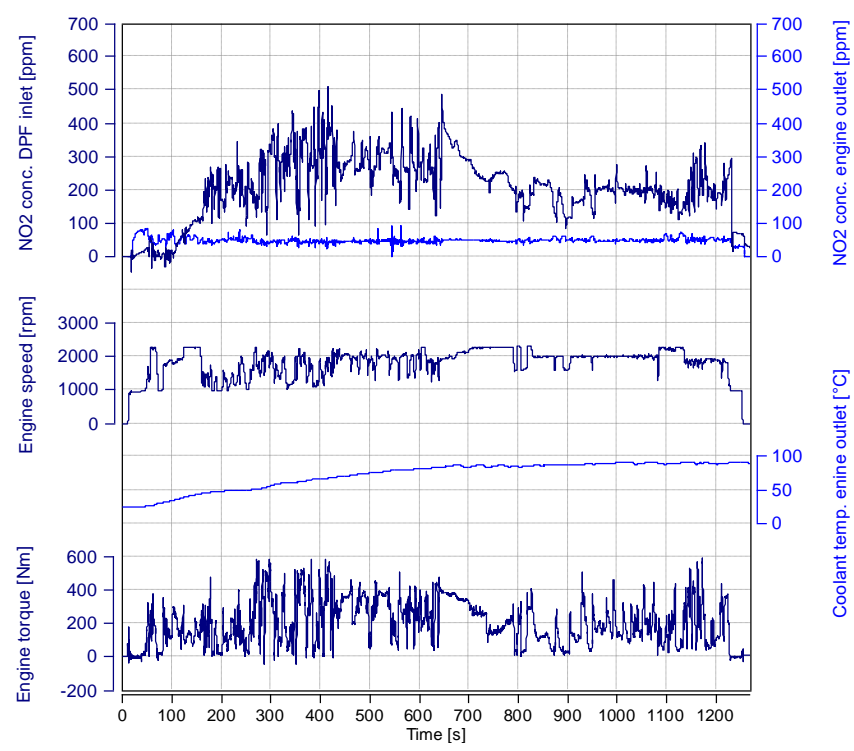

Fig. 7. $\mathrm{NO}_{2}$ concentrations measured during the NRTC cold cycle

The engine outlet $\mathrm{NO}_{2}$ values oscillated around 40-70 $\mathrm{ppm}$, whereas downstream of the DOC (DPF inlet), the $\mathrm{NO}_{2}$ reached a level of $100-500 \mathrm{ppm}$, depending on the engine operating point. An exception was noted during the first 130s of the test run, in which the engine outlet $\mathrm{NO}_{2}$ level is greater than the DPF inlet one. Such behavior can be observed until the converter's light-off temperature is reached. The presence of $\mathrm{NO}_{2}$ in exhaust gas is key for effective execution of passive regeneration. To assess the magnitude of DPF loading under transient operating conditions, continuous measurement of the soot concentration at the engine-out position was carried out. 


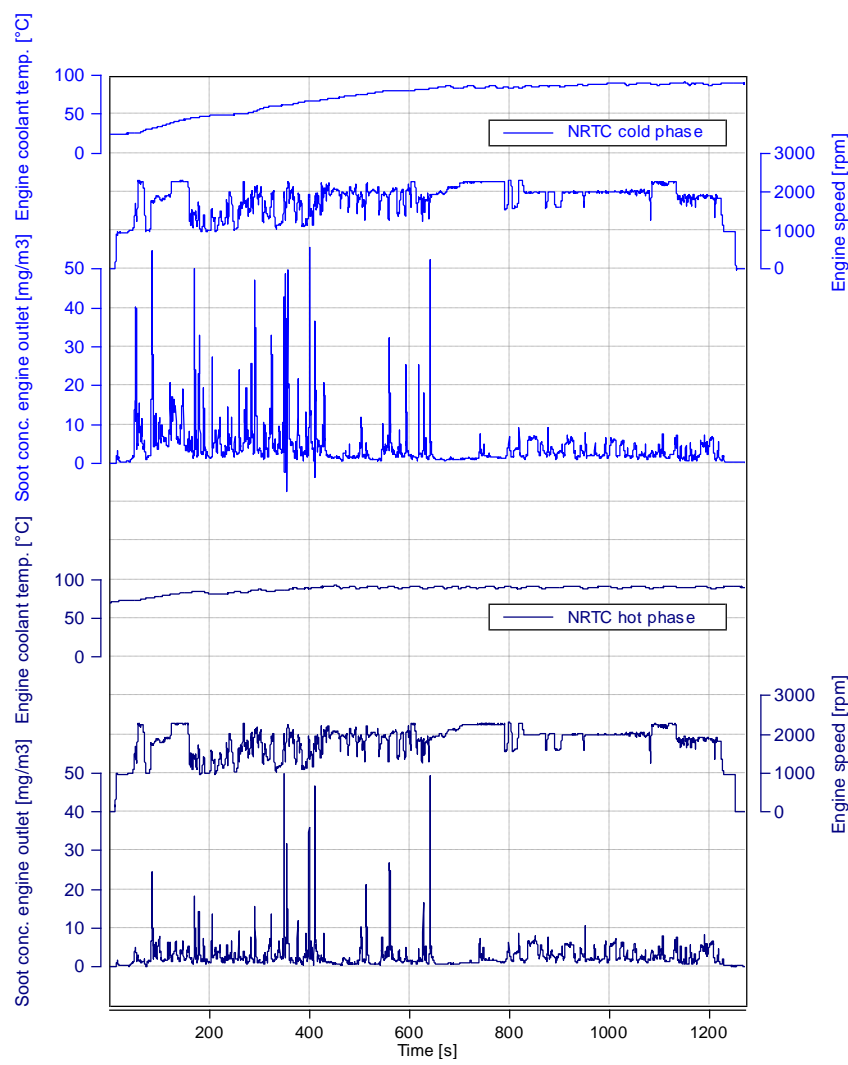

Fig. 8. Soot concentration measurement during the NRTC cold and hot cycles

Figure 8 shows the trace of soot concentration during the cold and hot phases of the NRTC test. An increased level of soot concentration was observed during the first 400 seconds of the cold NRTC phase. After the engine warm up to ca. $70^{\circ} \mathrm{C}$ coolant temperature, the soot concentration in both the cold and hot phases remained comparable.

\subsection{Balance point test}

The balance point test was performed on the DOC-DPF system only. The test consisted of 9 steady-state engine operating points, with each lasting approx. 20 minutes. The engine speed was fixed at one set value, while the engine load was varied so as to achieve a stepwise increase of gas temperature of $25-30^{\circ} \mathrm{C}$ for each successive test step.

The filter equilibrium between soot loading and soot oxidation was found at ca. $330^{\circ} \mathrm{C}$, as marked by the cursor position in Fig. 9. This corresponded to a pressure drop across the DOC-DPF system of around 115 mbar, a value specific for that exhaust system layout.

The engine operation below an exhaust temperature of $330^{\circ} \mathrm{C}$ resulted in a steady increase in filter pressure drop, thus leading to the filter filling up with particulate and eventually clogging. To prevent such a situation during infield operation, the active filter regeneration strategy needs to be implemented within the ECU.

On the other hand, in the case of exhaust gas temperatures greater than $330^{\circ} \mathrm{C}$, the filter pressure drop decreased over time, thereby ensuring trouble-free operation considering steady-state operation.

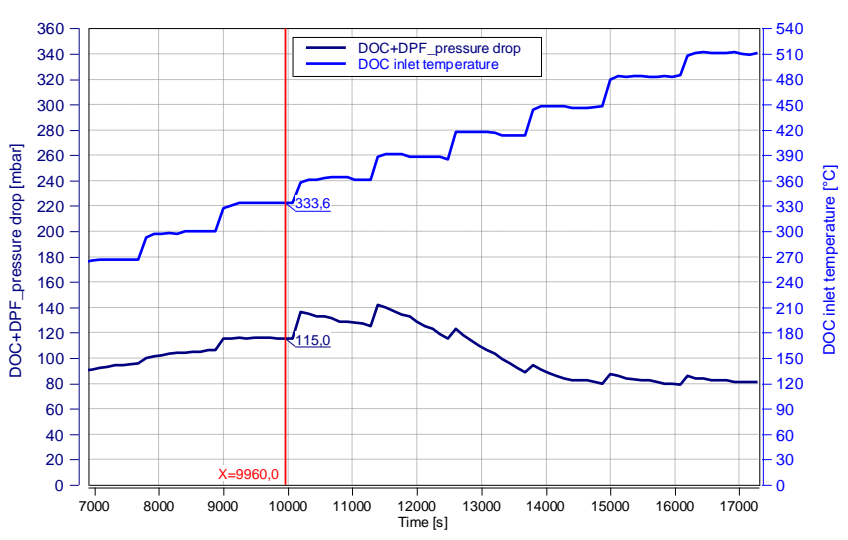

Fig. 9. DOC-DPF balance point test results

Short events of filter pressure drop increases were related to the transitions between test steps. Above a DOC inlet temperature of $360^{\circ} \mathrm{C}$, the filter's capability for passive regeneration further increased, to levels significantly exceeding the rate of soot input into the filter. A strong decrease in filter pressure drop was observed until the DOCDPF system had been completely cleaned up.

\subsection{Pressure drop test}

The DOC-DPF system was characterized by the measurement of the pressure drop curve that was plotted as a function of the exhaust mass flow rate. The pressure drop test lasted 15 minutes and aimed at evaluation of the gas flow resistance of the system. The test was run twice: at the beginning (SOT) and at the end (EOT) of the entire test program.

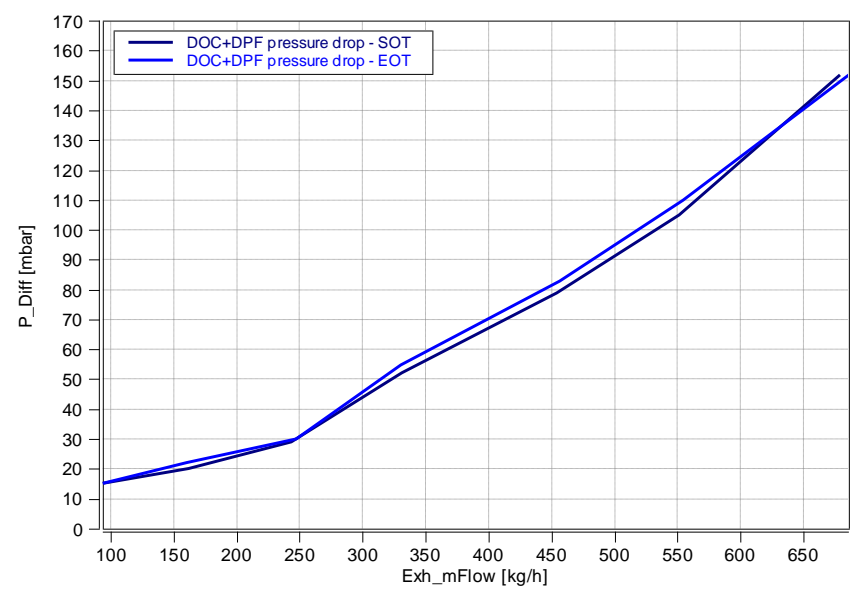

Fig. 10. DOC-DPF pressure drop test results

To determine the pressure drop curve, the test was started in the cleaned-up condition, after performing an active filter regeneration event. Measured test results are shown in Fig. 10. The maximum DOC-DPF delta pressure reached the value of ca. 150 mbar at the highest gas flow rate of 700 $\mathrm{kg} / \mathrm{h}$. The curve got steeper in shape after passing the point of $250 \mathrm{~kg} / \mathrm{h}$ of gas flow.

Pressure drop tests run at SOT and EOT did not revealed any physical damages in the system that may occurred throughout the test program. 


\subsection{Filter loading and passive regeneration}

\subsubsection{Filter loading}

The filter soot loading phase was performed in the steady-state conditions with limited the occurrence of passive regeneration. The filter inlet temperature was set to not exceed the $290^{\circ} \mathrm{C}$, so below the balance point temperature.

The target amount of soot to be collected inside the DPF was $20 \mathrm{~g}$ and the length of loading time was calculated on the basis of the smoke value and Equations 1 and 2. The real mass of the soot accumulated inside the DPF was determined by periodical filter deinstallation from the exhaust line and weighing on a balance under defined (hot) conditions. Figure 11 presents the DPF delta pressure curve during the test.

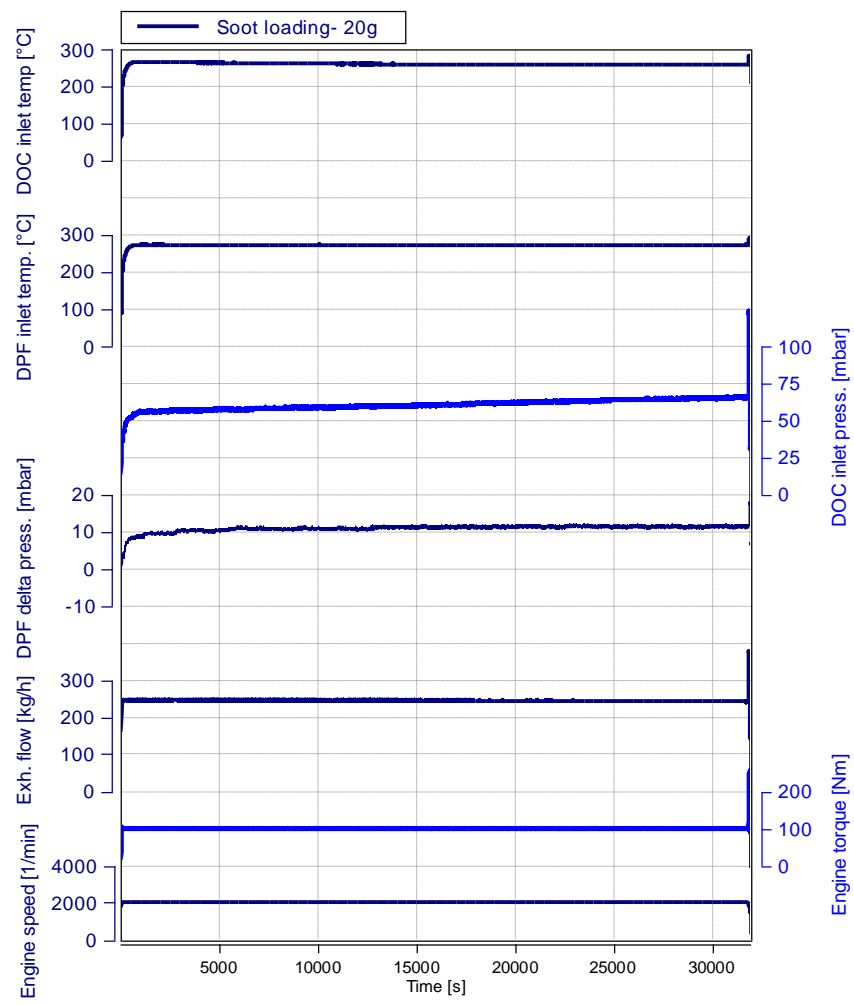

Fig. 11. Filter loading phase for passive regeneration

The test parameters related to engine operation, such as engine speed, torque and outlet gas temperature remained stable over time.

\subsubsection{Passive filter regeneration}

Following the filter loading phase to reach the target soot mass, passive filter regeneration was initialized. The engine operating point was changed to run at high output in order to achieve a gas temperature of $400^{\circ} \mathrm{C}$ (measured at the DPF inlet). The fuel post injection was not activated in this scenario. Figure12 illustrates the tendency of decreasing DOC inlet gas pressure and, at the same time, only a slight impact of passive regeneration on the DPF pressure drop.

The passive regeneration lasted until the amount of soot mass accumulated in the loading phase was completely burned out. Subsequently, the DPF was weighed and the soot burning efficiency was assessed.

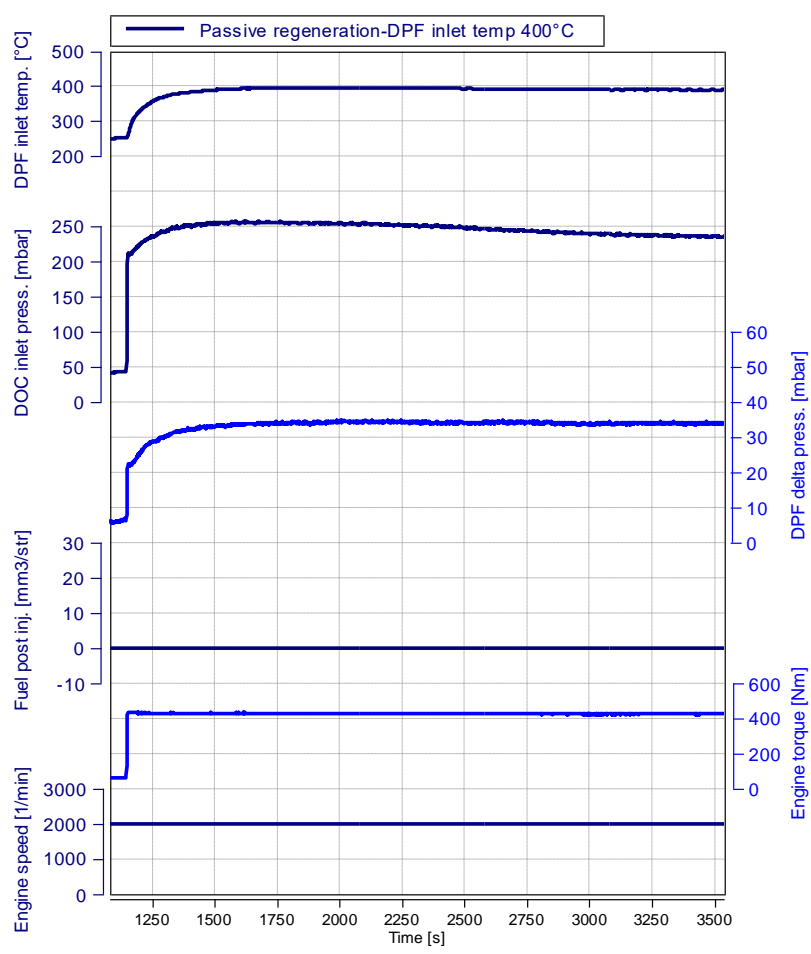

Fig. 12. Passive regeneration of the filter

\subsection{Filter loading and active regeneration}

\subsubsection{Filter loading}

The filter loading for the active regeneration event was performed in a similar way as for the passive one. The only difference in the loading procedure was that the target soot mass was increased to $40 \mathrm{~g}$. This greater level of soot accumulation was achieved by extending the duration of loading phase. The inlet DOC and delta DPF pressure curves are shown in Fig. 13.

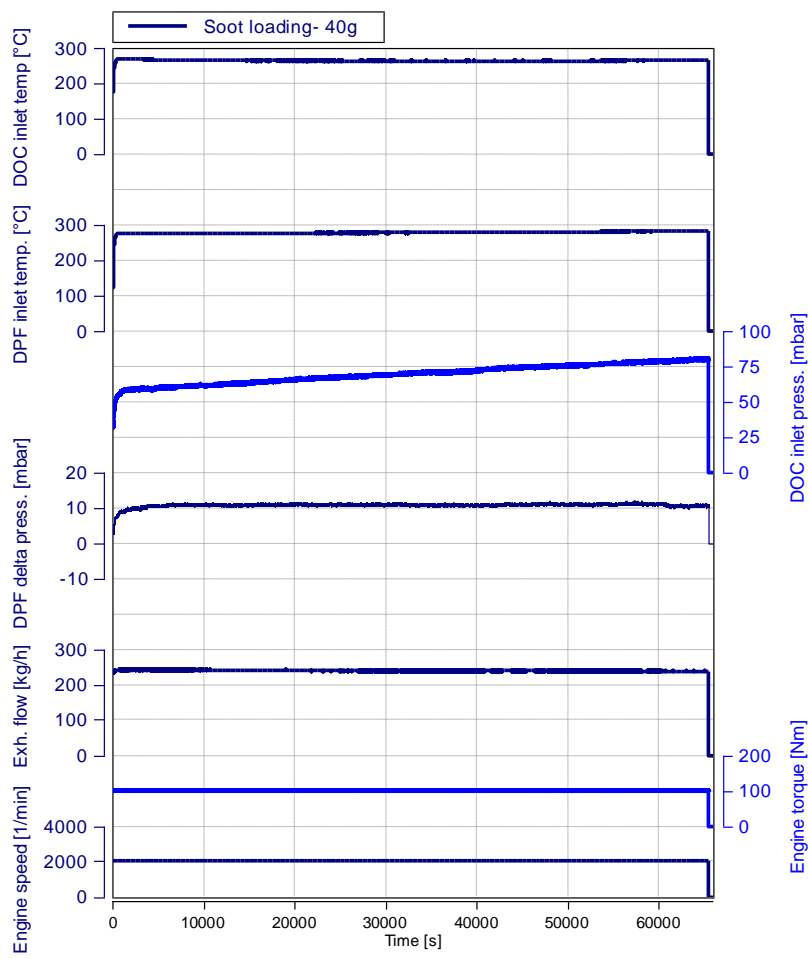

Fig. 13. Filter loading phase for active regeneration 


\subsubsection{Active filter regeneration}

The active filter regeneration was run at $600^{\circ} \mathrm{C}$ gas temperature (measured at the DPF inlet; Fig. 14).

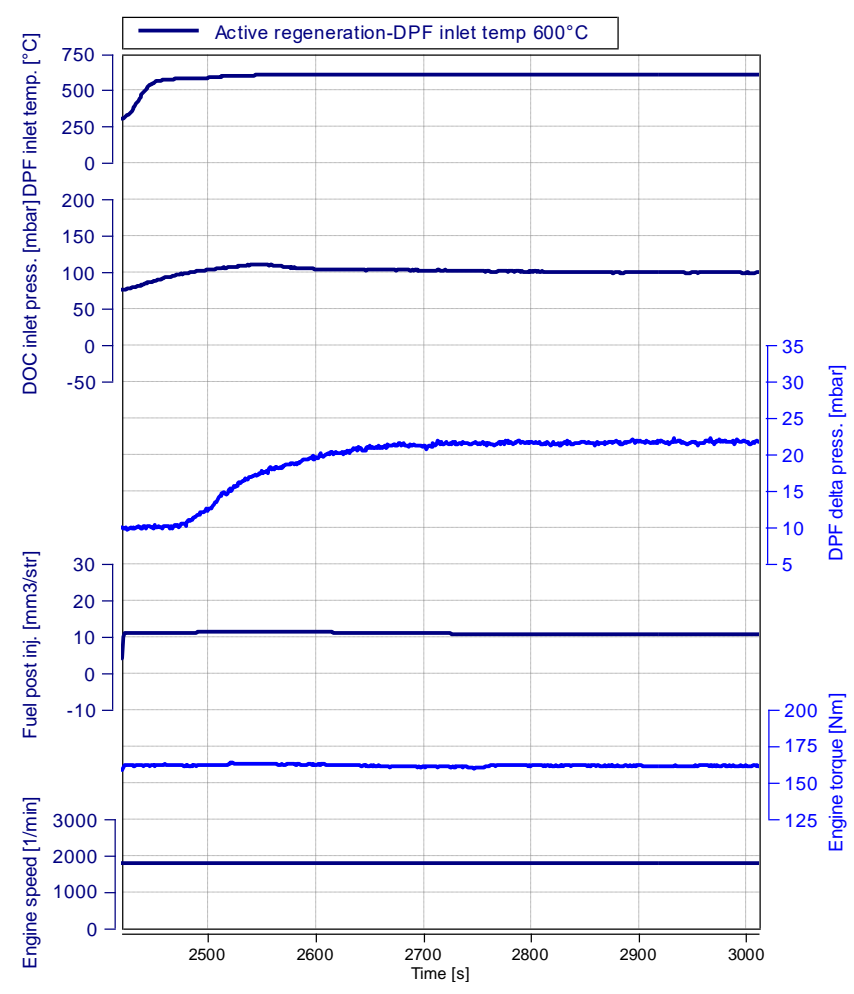

Fig. 14. Active filter regeneration
Elevated gas temperature was achieved by fuel post injection, with the quantity controlled by the ECU via ETAS/INCA interface. The regeneration event lasted ca. $600 \mathrm{~s}$, which was found to be sufficient to fully oxidase the accumulated soot. Subsequently, the DPF was weighed and the soot burning efficiency was assessed.

\section{Conclusion}

This paper presents a methodology for diesel particulate filter testing performed on an engine dynamometer. The research work conducted provided background information on filter performance in terms of soot loading characteristics and the capabilities of soot oxidation under passive or active regeneration events. The filter was coupled with DOC converter installed in the upstream position. As a DOC-DPF system, it was characterized for emission performance including $\mathrm{NO}_{2}$ formation, gas flow resistance and the equilibrium gas temperature that allowed safe engine operation without the necessity of triggering active filter regeneration.

For the overall engine and aftertreatment system evaluation, the NRTC and NRSC legislative cycles were performed.

The examples of filter soot loading and regeneration process were presented for engine testing laboratory conditions.

Close analysis of the exhaust system parameters under operation on a test bench is necessary to understand and predict the system behavior during in-field operation of the vehicle or machinery. It allowed to control the system functionality in an effective way, avoiding any malfunctions caused by gas temperature exceedances or filter clogging.

\section{Nomenclature}

ASC ammonia slip catalyst

ATS aftertreatment system

CI compression ignition

CLD chemiluminescence detector

CO carbon oxide

CPSI cells per square inch

DI direct injection

DOC diesel oxidation catalyst

DPF diesel particulate filter

ECU engine control unit

HC hydrocarbons

FID flame ionization detector

FSN filter smoke number
ISO International Organization for Standardization

NDIR nondispersive infrared

$\mathrm{NO}_{\mathrm{x}} \quad$ nitrogen oxides

$\mathrm{NO}$ nitrogen oxide

$\mathrm{NO}_{2} \quad$ nitrogen dioxide

NRSC Non-Road Stationary Cycle

NRTC Non-Road Transient Cycle

PGM Platinum Group Metals

PM particulate matter

PMD paramagnetic detection

ppm parts per million

SCR Selective Catalytic Reduction

\section{Bibliography}

[1] EUROPEAN AUTOMOBILE MANUFACTURERS ASSOCIATION, ACEA. Medium and heavy trucks over $3.5 \mathrm{t}$ new registrations by fuel type in the European Union. 2020:https://www.acea.auto/files/ACEA_trucks_by_fuel_ty pe_full-year-2020.pdf (accessed on 06.2021).

[2] GOYAL, P., JAISWAL, N., KUMAR, A. et al. Air quality impact assessment of $\mathrm{NO}_{\mathrm{x}}$ and $\mathrm{PM}$ due to diesel vehicles in Delhi. Transportation Research Part D: Transport and Environment. 2010, 15(5), 298-303.

https://doi.org/10.1016/j.trd.2010.03.002
[3] POURAZAR, J., FREW, A.J., BLOMBERG, A. et al. Diesel exhaust exposure enhances the expression of IL-13 in the bronchial epithelium of healthy subjects. Respiratory Medicine. 2004, 98(9), 821-825.

https://doi.org/10.1016/j.rmed.2004.02.025

[4] NEEFT, J.P.A., MAKKEE, M., MOULIJN, J.A. Diesel particulate emission control. Fuel Processing Technology. 1996, 47(1), 1-69. https://doi.org/10.1016/0378-3820(96)01002-8 
[5] FINO, D., SPECCHIA, V. Open issues in oxidative catalysis for diesel particulate abatement. Powder Technology. 2008, 180(1-2), 64-73.

https://doi.org/10.1016/j.powtec.2007.03.021

[6] FLEISCHMAN, R., AMIEL, R., CZERWINSKI, J. et al. Buses retrofitting with diesel particle filters: Real-world fuel economy and roadworthiness test considerations. Journal of Environmental Sciences. 2018, 67, 273-286, https://doi.org/10.1016/j.jes.2017.09.011

[7] ISO 8178. Reciprocating Internal Combustion Engines. Exhaust Emission Measurement.

[8] KOTUS, M., PEXA, M., KUBÍN, K. Modelling of non-road transient cycle - comparison of three tractors. Journal of Central European Agriculture. 2013, 14(4), 1281-1294. https://doi.org/10.5513/JCEA01/14.4.1344

[9] WORLDWIDE EMISSIONS STANDARDS. On and offhighway commercial vehicles. Delphi Technologies. 2018/2019.

[10] DIESELNET. https://dieselnet.com (accessed on 08.2021).

Rafał Sala, DEng. - Engine Research Department, BOSMAL Automotive Research and Development Institute Ltd, Poland.

e-mail: rafal.sala@bosmal.com.pl
[11] COOPER, B.J., THOSS J.E. Role of NO in diesel particulate emission control. SAE Technical Paper 890404. 1989. https://doi.org/10.4271/890404

[12] ALLANSSON, R., BLAKEMAN, P.G., COOPER, B.J. et al. Optimising the low temperature performance and regeneration efficiency of the continuously regenerating diesel particulate filter (CR-DPF) system. SAE Technical Paper 200201-0428. 2002. https://doi.org/10.4271/2002-01-0428

[13] MAJEWSKI, W.A. Diesel filter regeneration. https://dieselnet.com (accessed on 08.2021).

[14] NORTHROP, W.F., BOHAC, S.V., CHIN, J-Y. et al. Comparison of filter smoke number and elemental carbon mass from partially premixed low temperature combustion in a direct-injection diesel engine. Journal of Engineering for Gas Turbines and Power. 2011, 133(10), 102804. https://doi.org/10.1115/1.4002918

[15] Smoke value measurement with the filter-paper-method. AVL Application Notes. 2005, AT1007E, Rev. 02.

Witold Konior - Engine Research Department, BOSMAL Automotive Research and Development Institute Ltd, Poland.

e-mail: witold.konior@bosmal.com.pl

Kamil Kołek - Engine Research Department, BOSMAL Automotive Research and Development Institute Ltd, Poland.

e-mail:kamil.kolek@bosmal.com.pl 